\title{
Applying Spermidine for Differential Responses of Antioxidant Enzymes in Cucumber Subjected to Short-term Salinity
}

\author{
Chang-Xia Du', Huai-Fu Fan', and Shi-Rong Guo ${ }^{2}$ \\ Key Laboratory of Southern Vegetable Crop Genetic Improvement in Ministry of Agriculture, College \\ of Horticulture, Nanjing Agricultural University, Nanjing 210095, People's Republic of China \\ Takafumi Tezuka \\ Division of Biological Science, Graduate School of Science, Nagoya University, Nagoya 464-8601, \\ Japan
}

\begin{abstract}
Additional INDEX words. $\mathrm{NaCl}$ stress, Cucumis sativus, oxidative injury, exogenous substance, enzyme activity, isozyme
Abstract. To examine whether spermidine (SPD) modifies plant antioxidant enzyme expression in response to shortterm salt stress, cucumber (Cucumis sativus) seedlings were treated with $\mathrm{NaCl}$ in the presence or absence of SPD for 3 days. Compared with untreated control plants, free radical production and malondialdehyde content in leaves and roots increased significantly and plant growth was suppressed under $50 \mathrm{~mm}$ NaCl stress. Exogenous SPD sprayed on leaves at a concentration of $1 \mathrm{~mm}$ alleviated salinity-mediated growth reduction. Salt stress caused a consistent increase in soluble protein content, as well as peroxidase (POD) and superoxide dismutase (SOD) activities in cucumber seedlings. By native polyacrylamide gel electrophoresis, five POD isozymes were detected in cucumber seedling leaves, and seven in roots. We detected five SOD isozymes in leaves and four in roots, and two catalase (CAT) isozymes in leaves and two in roots. Our results indicate that salt stress induced the expression of POD and SOD isozymes in cucumber seedlings, but inhibited the expression of CAT isozymes in roots. Application of exogenous SPD further increased POD and SOD expression and activity, and led to the differential regulation of CAT in leaves and roots. These data show that antioxidant enzymes, especially POD and SOD, appear to protect cucumber seedlings against stress-related damage, and they appear to function as the molecular mechanisms underlying the response of cucumber seedlings to salinity. Moreover, SPD has potential to scavenge directly free radical and to alleviate growth inhibition and promote the activity and expression of antioxidant system enzymes in cucumber seedlings under shortterm salt stress.
\end{abstract}

The recent overutilization of chemical fertilizers has caused secondary salinization in Chinese greenhouses, and salinity is one of the major environmental factors limiting plant growth and yield (Parida and Das, 2005). The large accumulation of salt and salt ions may induce biochemical changes in greenhouse plants, such as the accumulation of reactive oxygen species (ROS). This accumulation will increase the level of oxidized species, thereby creating oxidative stress that can damage DNA, inactivate enzymes, and cause lipid peroxidation (Finkel and Holbrook, 2000; Moldovan and Moldovan, 2004). The most important forms of ROS are hydroxyl radicals, singlet oxygen, superoxide radicals, and hydrogen peroxide $\left(\mathrm{H}_{2} \mathrm{O}_{2}\right)$. Plants possess an endogenous mechanism to protect cellular and subcellular systems from the cytotoxic effects of ROS, which includes low-molecular-weight non-enzymatic antioxidants and enzymatic components (Agarwal and Pandey, 2004).

Superoxide dismutase (SOD) is a metalloprotein that catalyzes the dismutation of superoxide radicals to $\mathrm{H}_{2} \mathrm{O}_{2}$ and $\mathrm{O}_{2}$ (Bowler et al., 1992). The $\mathrm{H}_{2} \mathrm{O}_{2}$ is then scavenged by catalase (CAT) and a variety of peroxidases (POD) and converted into

Received for publication 16 Nov. 2009. Accepted for publication 16 Dec. 2009. This work was supported by the National Basic Research Programme of China (973 Programme; No. 2009CB119000) and by the National Nature Science Foundation of China (No. 30900995).

${ }^{1}$ These authors contributed equally to this work

${ }^{2}$ Corresponding author. E-mail: srguo@njau.edu.cn.
$\mathrm{H}_{2} \mathrm{O}$ and $\mathrm{O}_{2}$. The biochemical defense system also includes nonenzymatic constituents, such as glutathione, ascorbic acid, $\alpha$-tocopherols, and carotenoids (Apel and Hirt, 2004). In recent years, growing interest has focused on the idea that the regulation of these antioxidants by an exogenous substance might mediate plant tolerance to salt stress.

Polyamines (PAs) are low-molecular-weight aliphatic amines that are ubiquitous in all organisms. Common natural PAs include the higher PAs, spermine (SPM) and spermidine (SPD), and their diamine obligate precursor putrescine (PUT). These PAs are absolutely necessary for normal cell growth. At physiological $\mathrm{pH}, \mathrm{PAs}$ have been shown to influence protein synthesis, DNA-protein interactions (van den Broeck et al., 1994), and membrane integrity (Tiburcio et al., 1994). In plants, PAs are believed to play an important protective role against various environmental stresses, such as osmotic stress, salinity, heat, chilling, hypoxia, and mineral nutrient deficiencies (Bouchereau et al., 1999). Among the three major PAs (SPM, SPD, and PUT), SPD has, in many cases, been most closely associated with stress tolerance in plants (Kasukabe et al., 2004; Shen et al., 2000). Shen et al. (2000) sprayed cucumber leaves with $1 \mathrm{~mm}$ PAs (PUT, SPD, or SPM) and found that SPD prevented chill-induced superoxide formation and CI. Exogenous $1 \mathrm{~mm}$ SPD sprayed on maize (Zea mays) leaves could alleviate the effect of $\mathrm{NaCl}$ (Jiang et al., 2000). SPD application to salinized nutrient solution resulted in an increase in polyamine and proline contents and antioxidant enzyme activities in cucumber seedlings, which contributed osmotic adjustment 
during salinity (Duan et al., 2008). In water-stressed cucumber plants, Kubiś (2008) showed that exogenous application of SPD with $1 \mathrm{~mm}$ concentration, due to a higher concentration ( $3 \mathrm{~mm}$ ) with negative influence and lower $(0.1 \mathrm{~mm})$ with very limited effect, moderated the activities of scavenging system enzymes and influenced oxidative stress levels.

Cucumber is one of the most important vegetables worldwide. It is highly sensitive to salinity, especially during germination and in the early stages of development (Baysal and Tipirdamaz, 2007). The effect of SPD on isozymes of antioxidant enzymes (SOD, POD, and CAT) in cucumber seedlings treated with $\mathrm{NaCl}$ is unknown. To answer this question, leaves and roots were harvested from treated and untreated plants to measure growth, antioxidant enzyme activity, and isozyme expression. The objective of the present study was to assess the influence of SPD sprayed on leaves on the activity of antioxidant enzymes and isozymes in cucumber seedlings subjected to short-term salt stress. In addition, isozymes and other genetic information regarding horticulturally important traits may be useful for defining a cucumber core collection.

\section{Materials and Methods}

Cucumber (cv. Jinchun No.2) seeds were germinated on moist filter paper in the dark at $28^{\circ} \mathrm{C}$ for $30 \mathrm{~h}$. The germinated seedlings were transferred to plastic trays $(41 \times 41 \times 5 \mathrm{~cm})$ containing quartz sand and were grown in a greenhouse at Nanjing Agricultural University at 25 to $30{ }^{\circ} \mathrm{C}$ day/ 15 to $18{ }^{\circ} \mathrm{C}$ night under natural light. Relative humidity in the greenhouse ranged between $60 \%$ and $75 \%$. When the cotyledons expanded, seedlings were supplied with water containing one-halfstrength Hoagland's nutrient solution $(\mathrm{pH} 6.5 \pm 0.1$, EC 2.0 $\left.2.2 \mathrm{dS} \cdot \mathrm{m}^{-1}\right)$. After full development of the third leaf of each plant, 12 seedlings of uniform size were transplanted into each of three plastic containers $(51 \times 33 \times 20 \mathrm{~cm})$ filled with fullstrength Hoagland's nutrient solution and renewed every $2 \mathrm{~d}$. The nutrient solutions were kept at 20 to $25{ }^{\circ} \mathrm{C}$ and were continuously aerated using an air pump at an interval of $20 \mathrm{~min}$ to maintain the dissolved oxygen at $8.0 \pm 0.2 \mathrm{mg} \cdot \mathrm{L}^{-1}$.

After $3 \mathrm{~d}$ of pre-culture, the treatments were started. The cucumber seedlings were treated as follows: 1) control plants were grown in Hoagland's solution, 2) salt-treated plants were grown in Hoagland's solution plus $50 \mathrm{~mm} \mathrm{NaCl}$, and 3) supplemental SPD plants were grown in Hoagland's solution plus $50 \mathrm{~mm} \mathrm{NaCl}$ and the leaves were sprayed with $1 \mathrm{~mm}$ SPD. The leaves of the control and salt-treated plants were sprayed with distilled water. Tween-20 $(0.5 \%$, v/v) was used as surfactant. Three days after beginning $\mathrm{NaCl}$ treatment, the fully expanded third leaves and the middle part of roots were harvested, immediately frozen in liquid nitrogen, and stored at $-80{ }^{\circ} \mathrm{C}$ until required for analyzing free radical production, malondialdehyde (MDA) content, enzyme assay, and isozyme analysis.

The area of the third and fourth leaf, total root length, and number of root tips on a plant were measured using a scanner (Expression 1680; Epson America, Long Beach, CA) and image analysis software WinRHIZO (Regent Instruments, Quebec, QC, Canada). Before determination of fresh weight, the seedlings were uprooted from the culture medium and washed using deionized water. Shoots and roots were separated. After measuring the fresh weight, samples were dried in an oven at $105^{\circ} \mathrm{C}$ for $15 \mathrm{~min}$ followed by $75^{\circ} \mathrm{C}$ for $72 \mathrm{~h}$, and the dry weight was then measured. Relative growth rate (RGR) was defined as the parameter RGR in the equation (Hunt, 1990):

$$
\begin{aligned}
\mathrm{RGR}= & \frac{\ln (\mathrm{W} 2)-\ln (\mathrm{W} 1)}{\mathrm{t} 2-\mathrm{t} 1} \cdot \mathrm{W} 1 \text { and } \mathrm{W} 2 \text { are the whole plant } \\
& \text { fresh weights at times } \mathrm{t} 1 \text { and } \mathrm{t} 2 .
\end{aligned}
$$

For enzyme activities, samples ( $1 \mathrm{~g})$ were harvested directly into liquid nitrogen and homogenized in $1.0 \mathrm{~L}$ of extraction buffer (50 mg PVP, $1 \mathrm{~mm}$ PMSF, $10 \mathrm{~mm}$ DTT, and $0.1 \mathrm{~mm}$ EDTA, in $50 \mathrm{~mm}$ potassium phosphate buffer, $\mathrm{pH}$ 7.8). The homogenate was centrifuged at $19,000 \mathrm{~g}_{\mathrm{n}}$ for $20 \mathrm{~min}$ at $4{ }^{\circ} \mathrm{C}$, and the supernatant was re-centrifuged again at $19,000 \mathrm{~g}_{\mathrm{n}}$ for $20 \mathrm{~min}$ at $4{ }^{\circ} \mathrm{C}$ for determination of enzyme activities. The protein concentration of the enzyme extract was determined according to the Bradford (1976) method using bovine serum albumin as a standard.

POD activity was measured according to the method of Kochba et al. (1977). One unit of activity was defined as the amount of enzyme required to increase the optical density at $470 \mathrm{~nm} \cdot \mathrm{min}^{-1}$ by 1 absorbance unit. SOD and CAT activity was assayed according to Dhindsa et al. (1981). One unit of SOD activity was defined as the amount of enzyme required to cause $50 \%$ inhibition of the photochemical reduction of nitroblue tetrazolium (NBT) and was monitored at $560 \mathrm{~nm}$. One unit of CAT activity was defined as the amount of enzyme required to decrease the optical density at $240 \mathrm{~nm} \cdot \mathrm{min}^{-1}$ by 0.1 absorbance units.

Native polyacrylamide gel electrophoresis (PAGE) was performed at $100 \mathrm{~V}$ for $60 \mathrm{~min}$ at $4{ }^{\circ} \mathrm{C}$, and then at $200 \mathrm{~V}$ for $\approx 180 \mathrm{~min}$. Electrophoresis buffer and gels were prepared as described by Laemmli (1970), with the exception that sodium dodecyl sulfate was excluded. The activity stain for each enzyme was carried out as described below. To separate CAT isozymes, native PAGE was performed using 7.5\% polyacrylamide gels. CAT was visualized on the gel using the method of Woodbury et al. (1971). After electrophoretic separation, the gel was incubated in $0.003 \% \mathrm{H}_{2} \mathrm{O}_{2}$ for 10 to $15 \mathrm{~min}$, washed with distilled water twice, and then incubated for 5 to $10 \mathrm{~min}$ in $1 \%$ ferric chloride and $1 \%$ potassium ferricyanide. After staining, the gel was carefully washed with tap water. To separate POD isozymes, native PAGE was performed using $7.5 \%$ polyacrylamide gels. POD isozymes were detected in gels as reported by Fielding and Hall (1978). The gel was incubated in a reaction buffer containing $25 \mathrm{~mm}$ potassium buffer ( $\mathrm{pH} 7.0$ ) for $15 \mathrm{~min}$ to lower the $\mathrm{pH}$. The gel was submerged again in a freshly prepared solution of $18 \mathrm{~mm}$ guaiacol and $25 \mathrm{mM} \mathrm{H}_{2} \mathrm{O}_{2}$ in $25 \mathrm{~mm}$ potassium phosphate buffer $(\mathrm{pH}$ 7.0) until the POD isozyme bands could be visualized. To separate SOD isozymes, native PAGE was performed using $10 \%$ polyacrylamide gels. SOD activity was detected by the procedure described by Beauchamp and Fridovich (1971). The gel was equilibrated with $36 \mathrm{~mm}$ potassium phosphate buffer $(\mathrm{pH} 7.8)$ containing $2.8 \times 10^{-5} \mathrm{M}$ riboflavin and $0.028 \mathrm{M} \mathrm{N}, \mathrm{N}, \mathrm{N}^{\prime}, \mathrm{N}^{\prime}$-tetramethylethylenediamine for $30 \mathrm{~min}$. The gel was washed in distilled water for $1 \mathrm{~min}$ and submerged with gentle agitation for 10 to $20 \mathrm{~min}$ in the same buffer as above containing $2.45 \mathrm{~mm}$ NBT. In the presence of light, the enzymes appeared as colorless bands on a purple background. All gels were then photographed.

Lipoxygenase (LOX) activity was measured spectrophotometrically according to a slight modification of the procedure 
outlined by Axelrod et al. (1981). The reaction substrate consisted of $1 \mathrm{M}$ linoleic acid $(25 \mu \mathrm{L})$ and $100 \mathrm{~mm}$ phosphate buffer $(\mathrm{pH} 6.0 ; 2925 \mu \mathrm{L})$. The reaction was started by adding $50 \mu \mathrm{L}$ of the enzyme solution at room temperature. One unit of LOX activity was defined as the amount of enzyme required to increase 0.1 absorbance at $234 \mathrm{~nm} \cdot \mathrm{min}^{-1}$. The superoxide anion $\left(\mathrm{O}_{2}{ }^{-}\right)$production rate was determined according to Elstner and Heupel (1976). $\mathrm{H}_{2} \mathrm{O}_{2}$ content was determined according to the titanium method of Patterson et al. (1984). MDA content was determined by the thiobarbituric acid reaction method (Heath and Packer, 1968).

Growth determinations were performed with 10 replicates. All other experiments were performed in triplicate. All data were statistically analyzed with SAS (version 8.2; SAS Institute, Cary, NC) using Duncan's multiple range test at a level of significance of 0.05 .

\section{Results}

Growth. In the present study, the fourth leaf area, shoot dry weight, root length, root dry weight, and RGR were significantly decreased $3 \mathrm{~d}$ after starting $\mathrm{NaCl}$ treatment $(P<0.05)$ compared with the control. Application of exogenous SPD (sprayed on leaves) alleviated the salinity-mediated growth reduction (Table 1 ).

Free radical production and membrane damage. Compared with the control, $\mathrm{O}_{2}{ }^{--}$production rate, $\mathrm{H}_{2} \mathrm{O}_{2}$ content, and MDA content increased significantly under salt stress. LOX activity in roots increased under salt stress, but decreased significantly in leaves. Exogenous SPD sprayed on leaves reduced salinity-induced free radical production and membrane damage, which was greater in roots than in leaves (Table 2).

SOLUble PROTEIN CONTENT AND ANTIOXIDANT ENZYME ACTIVITIES. As shown in Table 2, leaves contained protein levels eight times higher than those in roots. Under salt stress, root protein content was significantly increased (by 40\%) compared with the control, and leaf protein content was increased by $14 \%$. Application of exogenous SPD further elevated the protein content present in leaves, but slightly decreased the level in roots. Compared with the control, CAT activity in leaves increased $3 \mathrm{~d}$ after starting $\mathrm{NaCl}$ treatment $(P<0.05)$, and exogenous application of SPD further increased the activity. CAT activity in roots exhibited an opposite trend. Salt stress created different effects on POD activity. On the third day after treatment, salt stress greatly induced POD activity in roots and leaves $(P<0.05)$, and exogenous SPD further enhanced the induction of POD activity. Similar to POD, salt stress promoted the activity of SOD in cucumber seedling roots and leaves, and this effect was enhanced by application of exogenous SPD.

SOD, POD, AND CAT ISOzYMES. POD (Fig. 1), SOD (Fig. 2), and CAT (Fig. 3) isozymes of leaves and roots in cucumber seedlings were examined $3 \mathrm{~d}$ after starting treatment. Root POD activity (Table 2) was significantly higher than that in leaves, and a similar phenomenon was observed in POD isozyme profiles (Fig. 1). POD was present as five isozymes and seven isozymes in leaves (Fig. 1A) and roots (Fig. 1B), respectively. During the separation of these isozymes in native PAGE gels, we observed that POD isozymes were very susceptible to $\mathrm{NaCl}$ treatment in the presence and absence of SPD. In leaves (Fig. 1A), salt stress significantly increased the expression of all five POD isozymes (L-P1, L-P2, L-P3, L-P4, and L-P5). Exogenous SPD further increased the expression of L-P3, L-P4, and L-P5, but decreased L-P1 and L-P2. In roots, R-P1, R-P2, R-P3, R-P5, R-P6, and R-P7 bands appeared to increase significantly in response to salt stress (Fig. 1B) compared with the control. Exogenous SPD enhanced the L-P1, L-P4, L-P6, and L-P7 isozyme bands, and somewhat decreased the levels of L-P2 and L-P3. Remarkably, the R-P4 differed from those of other root POD isozymes in that it decreased in response to salt stress, and decreased even further in response to application of exogenous SPD.

We observed five SOD isozymes on native PAGE gels of cucumber seedling leaves (Fig. 2A). These bands were identified as L-S1, L-S2, L-S3, L-S4, and L-S5, and had relative mobility $\left(\mathrm{R}_{\mathrm{f}}\right)$ values of $0.358,0.368,0.637,0.743$, and 0.782 , respectively. The L-S4 band was the strongest band, while the L-S2 and L-S5 bands were weakest. With the exception of $\mathrm{L}-\mathrm{S} 5$, all SOD isozymes were enhanced by $\mathrm{NaCl}$ treatment. Exogenous SPD sprayed on leaves inhibited the L-S4 and L-S5 bands, and enhanced the L-S1, L-S2, and L-S3 bands. Compared with the control, four SOD isozyme bands (R-S1, R-S2, R-S3, and R-S4) present in roots (Fig. 2B) were enhanced by $\mathrm{NaCl}$ stress, and all four were further enhanced by SPD application.

Figure 3A shows that two CAT isozyme bands, L-C1 and $\mathrm{L}-\mathrm{C} 2$, were detected in cucumber seedling leaves. The L-C1 and

Table 1. Effect of exogenous application of $1 \mathrm{~mm}$ spermidine (SPD) on the growth parameters of cucumber seedlings exposed for $3 \mathrm{~d}$ to $50 \mathrm{~mm}$ $\mathrm{NaCl}$.

\begin{tabular}{|c|c|c|c|}
\hline \multirow[b]{2}{*}{ Treatments } & Control $^{z}$ & $\mathrm{NaCl}^{\mathrm{z}}$ & $\mathrm{NaCl}+\mathrm{SPD}^{\mathrm{z}}$ \\
\hline & \multicolumn{3}{|c|}{$(\text { mean } \pm \mathrm{SE})^{\mathrm{y}}$} \\
\hline The fourth leaf area $\left(\mathrm{cm}^{2} /\right.$ plant $)$ & $114.47 \pm 14.00 \mathrm{a}$ & $71.99 \pm 20.17 b$ & $93.89 \pm 10.42 \mathrm{a}$ \\
\hline Shoot dry wt (g/plant) & $1.65 \pm 0.13 \mathrm{a}$ & $1.39 \pm 0.11 \mathrm{~b}$ & $1.67 \pm 0.23 \mathrm{a}$ \\
\hline Number of root tips (no./plant) & $1323 \pm 60 a$ & $1019 \pm 105 b$ & $1101 \pm 78 b$ \\
\hline Root length $(\mathrm{cm})$ & $1106.30 \pm 77.21 \mathrm{a}$ & $824.55 \pm 100.52 b$ & $1129.18 \pm 86.49 \mathrm{a}$ \\
\hline Root dry wt (g) & $0.28 \pm 0.04 \mathrm{a}$ & $0.22 \pm 0.05 \mathrm{~b}$ & $0.27 \pm 0.08 \mathrm{ab}$ \\
\hline $\operatorname{RGR}\left(g \cdot g^{-1} \cdot d^{-1}\right)^{w}$ & $0.0937 \pm 0.0098 \mathrm{a}$ & $0.0355 \pm 0.0082 \mathrm{c}$ & $0.0611 \pm 0.097 \mathrm{~b}$ \\
\hline
\end{tabular}

${ }^{\mathrm{z} C o n t r o l}=$ control plants, $\mathrm{NaCl}=$ salt-treated plants, $\mathrm{NaCl}+\mathrm{SPD}=$ supplemental SPD plants.

${ }^{\mathrm{y}}$ Means of 10 replicates in three separate experiments.

'Different letters indicate significant differences between treatments via Duncan's multiple range test at $P<0.05$.

${ }^{\mathrm{w}} \mathrm{RGR}=$ relative growth rate. 


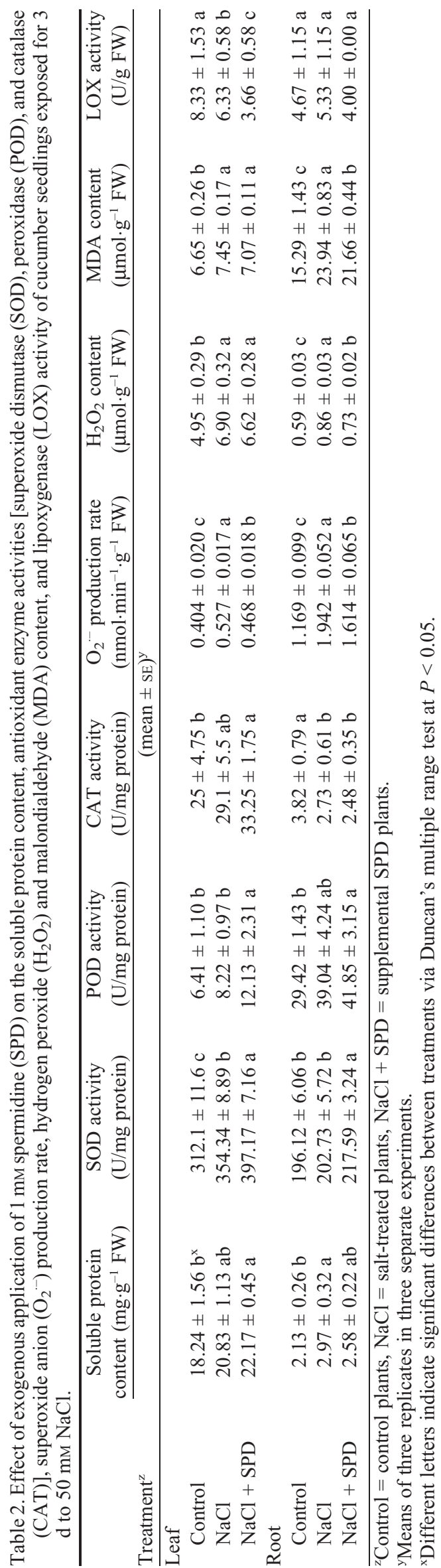

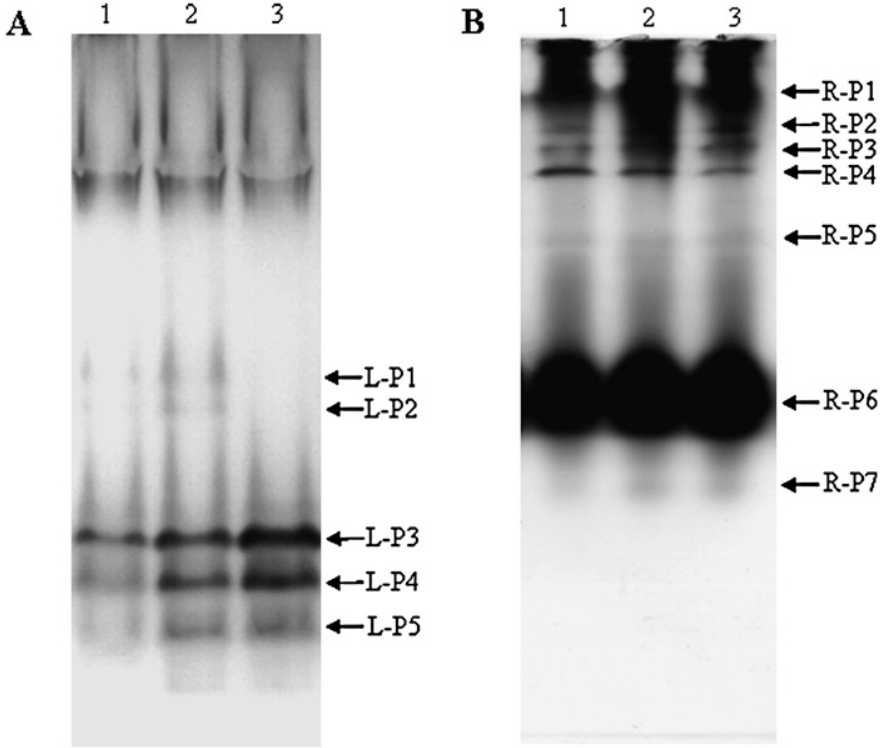

Fig. 1. Effect of exogenous application of $1 \mathrm{~mm}$ spermidine (SPD) on peroxidase (POD) isozymes in the leaf (A) and root (B) of cucumber seedlings exposed for $3 \mathrm{~d}$ to $50 \mathrm{~mm} \mathrm{NaCl}$. POD isozymes were detected on $7.5 \%$ native polyacrylamide gels $3 \mathrm{~d}$ after starting treatments (lane $1=$ control plants, lane 2 = salt-treated plants, lane $3=$ supplemental SPD plants). Arrows indicate the POD isozymes detected by staining.

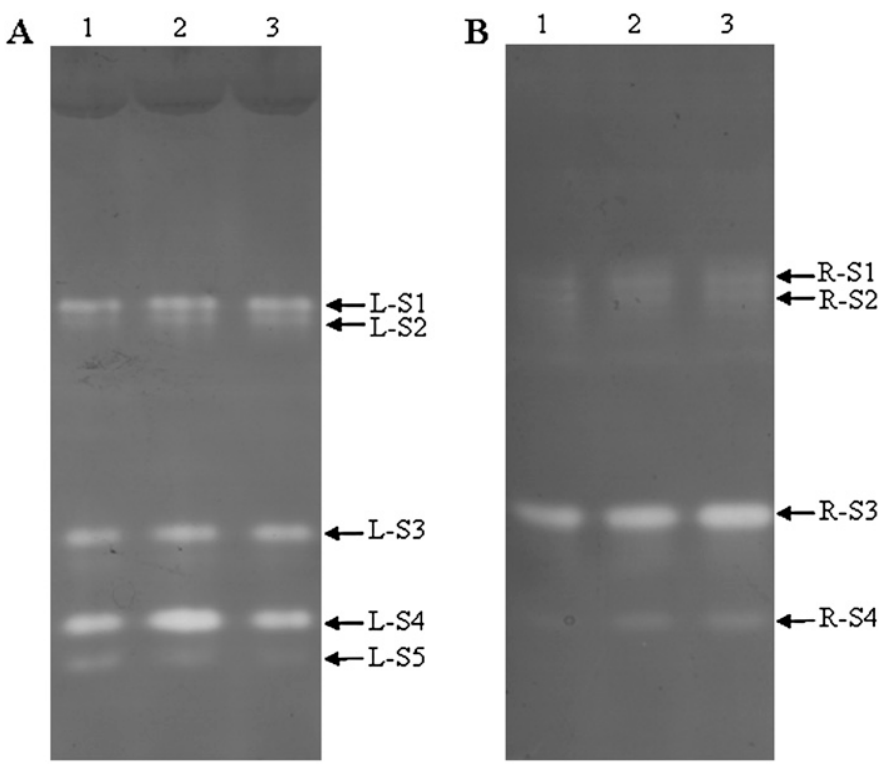

Fig. 2. Effect of exogenous application of $1 \mathrm{~mm}$ spermidine (SPD) on superoxide dismutase (SOD) isozymes in the leaf (A) and root (B) of cucumber seedlings exposed for $3 \mathrm{~d}$ to $50 \mathrm{~mm} \mathrm{NaCl}$. SOD isozymes were detected on $10 \%$ native polyacrylamide gels $3 \mathrm{~d}$ after starting treatments (lane $1=$ control plants, lane $2=$ salt-treated plants, lane $3=$ supplemental SPD plants). Arrows indicate the SOD isozymes detected by staining.

L-C2 band was induced and inhibited by $\mathrm{NaCl}$ stress, respectively, and application of exogenous SPD increased their expression. In cucumber seedling roots $\mathrm{R}-\mathrm{C} 1$ and $\mathrm{R}-\mathrm{C} 2$ were visualized on native PAGE gels (Fig. 3B). The isozyme bands were inhibited by salt stress, and exogenous SPD application increased slightly the R-C2 band and did not change the expression of R-C1. 


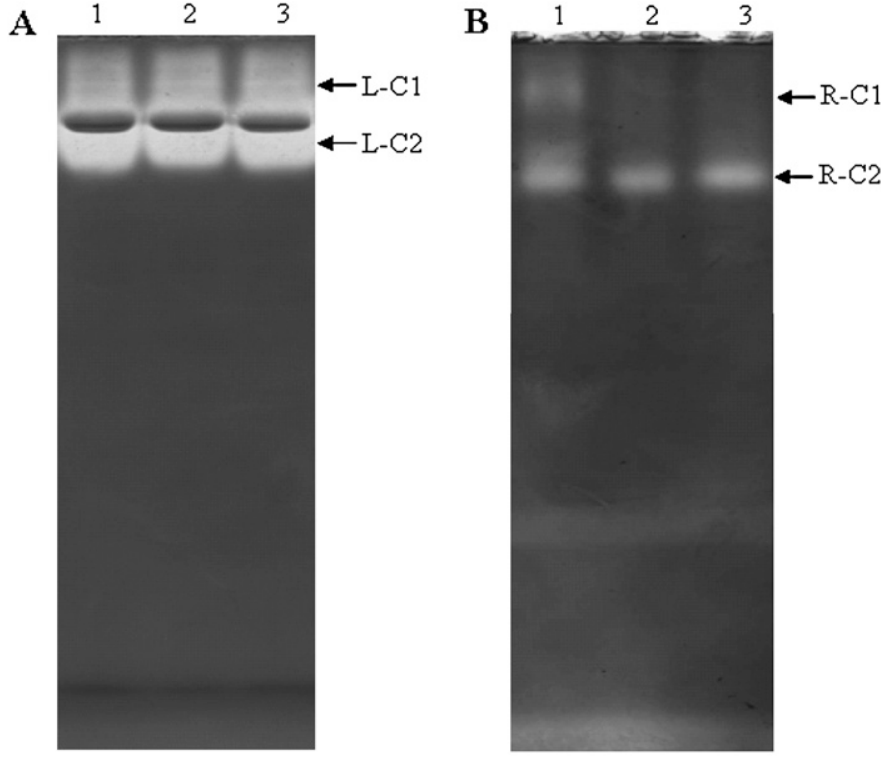

Fig. 3. Effect of exogenous application of $1 \mathrm{~mm}$ spermidine (SPD) on catalase (CAT) isozymes in the leaf (A) and root (B) of cucumber seedlings exposed for $3 \mathrm{~d}$ to $50 \mathrm{~mm} \mathrm{NaCl}$. CAT isozymes were detected on $7.5 \%$ native polyacrylamide gels $3 \mathrm{~d}$ after starting treatments (lane $1=$ control plants, lane 2 = salt-treated plants, lane 3 = supplemental SPD plants). Arrows indicate the CAT isozymes detected by staining.

\section{Discussion and Conclusions}

Growth analysis is a widely used analytical tool for characterizing plant growth. Of the parameters typically calculated, the most important is relative growth rate. In our study, RGR decreased significantly in cucumber seedlings exposed for $3 \mathrm{~d}$ to $50 \mathrm{~mm} \mathrm{NaCl}$, and plant growth was suppressed compared with the control (Table 1). The third leaf area did not significantly change due to salt stress because the leaf was almost fully expanded from the beginning of treatment. Exogenous SPD sprayed on cucumber leaves alleviated shortterm salinity-mediated growth reduction by varying degrees.

Our results showed that salt stress significantly increased free radical production and MDA content in cucumber seedling leaves and roots (Table 2). Exogenous SPD reversed the increase, which was greater in roots than in leaves. The effect of SPD sprayed on leaves on free radical production and MDA content in cucumber seedlings was similar to the effect of SPD application to roots via nutrient solution described by Duan et al. (2008). LOX is ubiquitous in plants and catalyzes dioxygenation of the plant fatty acids, linoleic and linolenic acids, has deleterious effects on membranes and proteins (Todd et al., 1990). In our study, however, salt stress significantly decreased LOX activity in leaves and increased slightly in roots, and LOX activities in leaves and roots were decreased by exogenous SPD. This implicates that it is probable that salt has not activated LOX in cucumber seedlings and that SPD may be associated more with LOX. Further study needs to proceed in our laboratory.

ROS are toxic molecules capable of injuring or even killing plant cells, and their level in cells must be tightly regulated (Mittler et al., 2004; Neill et al., 2002). To prevent ROS, various ROS-scavenging enzymes, including SOD, CAT, and POD, have been observed under salt stress. For example, it has been reported that ROS-scavenging enzymes increased under saline conditions in the shoots of soybean [Glycine max (Ghorbanli et al., 2004)], cucumber (Duan et al., 2008), and chickpea [Cicer arietinum (Kukreja et al., 2005)], but decreased in the roots of wheat [Triticum aestivum (Meneguzzo et al., 1999)] or were unaffected, as in the case of SOD in cucumber (Lechno et al., 1997) and CAT in soybean roots (Ghorbanli et al., 2004). In the present study, $\mathrm{NaCl}$ treatment increased the levels of SOD, the enzyme that converts superoxide to $\mathrm{H}_{2} \mathrm{O}_{2}$. However, with regard to enzymes that convert $\mathrm{H}_{2} \mathrm{O}_{2}$ to water, POD activity increased, whereas CAT decreased in roots. This suggests that POD plays a vital role in $\mathrm{H}_{2} \mathrm{O}_{2}$ detoxification under salt stress, but CAT in roots does not. Moreover, the decrease in CAT activity in response to salt stress is a phenomenon that occurs in many plant species (Corpas et al., 1993; Shim et al., 2003; Streb and Feierabend, 1996). In some cases, however, CAT activity increases following $\mathrm{NaCl}$ treatment, as observed in rice [Oryza sativa (Lin and Kao, 2000)] and cucumber (Lechno et al., 1997). This indicates that enzyme responses may vary according to the intensity of the stress, plant part, amount of time in which the plant has been stressed, and induction of new isozyme(s).

It is well documented that PAs counteract oxidative damage in plants by acting as direct free radical scavengers (Bors et al., 1989). SPD may act as a protectant for the plasma membrane against stress damage by maintaining membrane integrity (Roy et al., 2005). Moreover, it is probable that SPD acts as a signaling regulator in stress-signaling pathways (Kasukabe et al., 2004). In the present study, the effects of salinity on growth, free radical production, membrane damage, and antioxidant enzymes were modified by exogenous SPD application. Moreover, exogenous SPD significantly reduced salinityinduced increase of $\mathrm{O}_{2}{ }^{--}$and $\mathrm{H}_{2} \mathrm{O}_{2}$, but did not significantly increase ROS-scavenging enzyme activities during salt stress. Thus, it shows that SPD is potentially acting as direct free radical scavenger in cucumber seedlings treated with salinity.

Isozyme analysis has provided us with a relatively simple tool for evaluating gene flow, selection pressure, and genetic relationships (Gottlieb and Weeden, 1981). In isozyme charts, the color of the enzyme bands can reflect the relative quantity of the isozyme activity (Milone et al., 2003). Unlike most other organisms, plants possess multiple enzymatic forms of SOD. Three classes of SOD can be distinguished according to their metal cofactor and subcellular localization: copper/zinc, manganese, and iron forms (Bannister et al., 1987). The abundance of SOD isozymes is highly variable and is regulated by environmental and developmental stimuli (Bowler et al., 1992). In the present study, the majority of the SOD isozymes were induced by $\mathrm{NaCl}$ stress, and application of exogenous SPD increased the expression of some isozymes. The changes of these isozymes are consistent with activities, which further shows that SOD plays a protective role against environmental stress by converting superoxide to $\mathrm{H}_{2} \mathrm{O}_{2}$. POD possesses a large number of isozymes, and even more genes. Plant PODs are divided into three subgroups based on their pI: anionic, neutral, or cationic. The anionic POD isozymes have been studied most extensively with respect to their expression in response to developmental and environmental factors, including their possible role in plant defense (Huh et al., 1997). However, the available molecular and biochemical details of peroxidase function have not been well clarified in plant development and the stress response (Dalton et al., 1998). In the present 
experiment, activities and isozymes of POD were greatly increased in cucumber seedlings $3 \mathrm{~d}$ after treatment initiation. Salt stress increased the accumulation of the POD enzyme and the encoding gene was accelerated in response to salt stress. These results are in agreement with the findings of El-Baz et al. (2003) and Sreenivasulu et al. (1999). Application of SPD further induced the activity and expression of POD isozymes. Our results show that POD is one of the key antioxidant enzymes and contributes to protection against salt-induced oxidative stress in cucumber seedlings. Willekens et al. (1995) has proposed a classification for dicot CAT enzymes that relates primary structure with function. Class I is mainly associated with photorespiration, and Class III with fatty acid degradation in glyoxysomes. Class II may be particularly important for protection against environmental stress. In our study of the ROSmetabolizing enzymes examined, the CAT isozymes in roots decreased under salinity, consistent with activity. Detailed expression analyses of CAT in several plant species have clearly demonstrated that CAT isozymes are differentially, often even inversely, affected by stress conditions and accumulate in different cells or tissues of the plant (Willekens et al., 1995). The differential expression of CAT strongly suggests that each CAT isozyme has a specific cellular function.

In conclusion, short-term salt stress caused a clear suppression of plant growth. This inhibition could be reversed via exogenous application of SPD by spraying leaves. These experiments demonstrate that the altered expression of three antioxidant enzymes has a dramatic effect on the physiology and morphology of the plant. However, under induction treatment of the ROS-scavenging enzymes examined, changes in CAT enzymes are inconsistent with SOD and POD. By altering the expression of isozymes in metabolic pathways, it should be possible not only to delineate which isozyme is important, but also to determine the influence of salt stress on the antioxidant enzymes. These interactions are very complex and are related to the plant treatment time, tissues, species, and genotypes. Exogenous SPD greatly promoted the activity and expression of POD and SOD and alleviated the oxidative stress induced by salt stress in cucumber seedlings. Therefore, the protective role of SPD may be attributed to its ability to mediate the expression of genes encoding these ROS-scavenging enzymes under short-term salt stress.

\section{Literature Cited}

Agarwal, S. and V. Pandey. 2004. Antioxidant enzyme responses to $\mathrm{NaCl}$ stress in Cassia angustifolia. Biol. Plant. 48:555-560.

Apel, K. and H. Hirt. 2004. Reactive oxygen species: Metabolism, oxidative stress, and signal transduction. Annu. Rev. Plant Biol. 55:373-399.

Axelrod, B., T.M. Cheesbrough, and S. Laakso. 1981. Lipoxygenase from soybeans. Methods Enzymol. 71:441-451.

Bannister, J.V., W.H. Bannister, and G. Rotilio. 1987. Aspects of the structure, function, and applications of superoxide dismutase. CRC Crit. Rev. Biochem. 22:111-180.

Baysal, G. and R. Tipirdamaz. 2007. The effect of salinity on lipid peroxidation and some antioxidant enzyme activities in two cucumber cultivars. Acta Hort. 729:199-203.

Beauchamp, C. and I. Fridovich. 1971. Superoxide dismutase: Improved assays and an assay applicable to acrylamide gels. Anal. Biochem. 44:276-287.

Bors, W., C. Langebartels, C. Michel, and H. Sandermann. 1989. Polyamines as radical scavengers and protectants against ozone damage. Phytochemistry 28:1589-1595.
Bouchereau, A., A. Aziz, F. Larher, and J. Martin-Tanguy. 1999. Polyamines and environmental challenges: Recent development. Plant Sci. 140:103-125.

Bowler, C., M. Van Montagu, and D. Inzé. 1992. Superoxide dismutase and stress tolerance. Annu. Rev. Plant Physiol. Plant Mol. Biol. 43:83-116.

Bradford, M.M. 1976. A rapid and sensitive method for the quantitation of microgram quantities of protein utilizing the principle of proteindye binding. Anal. Biochem. 72:248-254.

Corpas, F.J., M. Gómez, J.A. Hernández, and L.A. del Río. 1993. Metabolism of activated oxygen in peroxisomes from two Pisum sativum L. cultivars with different sensitivity to sodium chloride. J. Plant Physiol. 141:160-165.

Dalton, D.A., S.L. Joyner, M. Becana, I. Iturbe-Ormaetxe, and J.M. Chatfield. 1998. Antioxidant defenses in the peripheral cell layers of legume root nodules. Plant Physiol. 116:37-43.

Dhindsa, R.S., P. Plumb-dhindsa, and T.A. Thorpe. 1981. Leaf senescence: Correlated with increased levels of membrane permeability and lipid peroxidation, and decreased levels of superoxide dismutase and catalase. J. Expt. Bot. 32:93-101.

Duan, J., J. Li, S. Guo, and Y. Kang. 2008. Exogenous spermidine affects polyamine metabolism in salinity-stressed Cucumis sativus roots and enhances short-term salinity tolerance. J. Plant Physiol. 165:1620-1635.

El-Baz, F.K., A.A. Mohamed, and A.A. Aly. 2003. Development of biochemical markers for salt stress tolerance in cucumber plants. Pak. J. Biol. Sci. 6:16-22.

Elstner, E.F. and A. Heupel. 1976. Inhibition of nitrate formation from hydroxylammonium chloride: A simple assay for superoxide dismutase. Anal. Biochem. 70:616-620.

Fielding, J.L. and J.L. Hall. 1978. A biochemical and cytochemical study of peroxidase activity in roots of Pisum sativum. J. Expt. Bot. 29:969-981.

Finkel, T. and N.J. Holbrook. 2000. Oxidants, oxidative stress and the biology of ageing. Nature 408:239-247.

Ghorbanli, M., H. Ebrahimzadeh, and M. Sharifi. 2004. Effects of $\mathrm{NaCl}$ and mycorrhizal fungi on antioxidative enzymes in soybean. Biol. Plant. 48:575-581.

Gottlieb, L.D. and N.F. Weeden. 1981. Correlation between subcellular location and phosphoglucose isomerase variability. Evolution 35:1019-1022.

Heath, R.L. and L. Packer. 1968. Photoperoxidation in isolated chloroplasts. I. Kinetic and stoichiometry of fatty acid peroxidation. Arch. Biochem. Biophys. 125:189-198.

Huh, G.-H., S.-J. Lee, Y.-S. Bae, J.R. Liu, and S.-S. Kwak. 1997. Molecular cloning and characterization of cDNAs for anionic and neutral peroxidases from suspension-cultured cells of sweet potato and their differential expression in response to stress. Mol. Gen. Genet. 255:382-391.

Hunt, R. 1990. Basic growth analysis: Plant growth analysis for beginners. Unwin Hyman, London.

Jiang, X.-Y., J. Song, H. Fan, and K.-F. Zhao. 2000. Regulations of exogenous calcium and spermidine on ion balance and polyamine levels in maize seedlings under $\mathrm{NaCl}$ stress. Acta Phytophysiol. Sinica 26:539-544.

Kasukabe, Y., L. He, K. Nada, S. Misawa, I. Ihara, and S. Tachibana. 2004. Overexpression of spermidine synthase enhances tolerance to multiple environmental stresses and up-regulates the expression of various stress-regulated genes in transgenic Arabidopsis thaliana. Plant Cell Physiol. 45:712-722.

Kochba, J., S. Lavee, and P. Spiegel-Roy. 1977. Differences in peroxidase activity and isoenzymes in embryogenic and nonembryogenic 'Shamouti' orange ovular callus lines. Plant Cell Physiol. 18:463-467.

Kubiś, J. 2008. Exogenous spermidine differentially alters activities of some scavenging system enzymes, $\mathrm{H}_{2} \mathrm{O}_{2}$ and superoxide radical levels in water-stressed cucumber leaves. J. Plant Physiol. 165:397406. 
Kukreja, S., A.S. Nandwal, N. Kumar, S.K. Sharma, S.K. Sharma, V. Unvi, and P.K. Sharma. 2005. Plant water status, $\mathrm{H}_{2} \mathrm{O}_{2}$ scavenging enzymes, ethylene evolution and membrane integrity of Cicer arietinum roots as affected by salinity. Biol. Plant. 49:305-308.

Laemmli, U.K. 1970. Cleavage of structural proteins during the assembly of the head of bacteriophage T4. Nature 227:680-685.

Lechno, S., E. Zamski, and E. Tel-Or. 1997. Salt stress-induced responses in cucumber plants. J. Plant Physiol. 150:206-211.

Lin, C.C. and C.H. Kao. 2000. Effect of $\mathrm{NaCl}$ stress on $\mathrm{H}_{2} \mathrm{O}_{2}$ metabolism in rice leaves. Plant Growth Regulat. 30:151-155.

Meneguzzo, S., F. Navari-Izzo, and R. Izzo. 1999. Antioxidative responses of shoots and roots of wheat to increasing $\mathrm{NaCl}$ concentrations. J. Plant Physiol. 155:274-280.

Milone, M.T., C. Sgherri, H. Clijsters, and F. Navari-Izzo. 2003. Antioxidative responses of wheat treated with realistic concentration of cadmium. Environ. Exp. Bot. 50:265-276.

Mittler, R., S. Vanderauwera, M. Gollery, and F. Van Breusegem. 2004. Reactive oxygen gene network of plants. Trends Plant Sci. 9:490-498. Moldovan, L. and N.I. Moldovan. 2004. Oxygen free radicals and redox biology of organelles. Histochem. Cell Biol. 122:395-412.

Neill, S., R. Desikan, and J. Hancock. 2002. Hydrogen peroxide signalling. Curr. Opin. Plant Biol. 5:388-395.

Parida, A.K. and A.B. Das. 2005. Salt tolerance and salinity effects on plants: A review. Ecotoxicol. Environ. Saf. 60:324-349.

Patterson, B.D., E.A. Mackae, and I.B. Ferguson. 1984. Estimation of hydrogen peroxide in plant extracts using titanium $(\chi)$. Anal. Biochem. 139:487-492.

Roy, P., K. Niyogi, D.N. SenGupta, and B. Ghosh. 2005. Spermidine treatment to rice seedlings recovers salinity stress-induced damage of plasma membrane and PM-bound $\mathrm{H}^{+}$-ATPase in salt-tolerant and salt-sensitive rice cultivars. Plant Sci. 168:583-591.
Shen, W., K. Nada, and S. Tachibana. 2000. Involvement of polyamines in the chilling tolerance of cucumber cultivars. Plant Physiol. 124:431-439

Shim, I.-S., Y. Momose, A. Yamamoto, D.-W. Kim, and K. Usui. 2003. Inhibition of catalase activity by oxidative stress and its relationship to salicylic acid accumulation in plants. Plant Growth Regulat. 39:285-292.

Sreenivasulu, N., S. Ramanjulu, K. Ramachandra-Kini, H.S. Prakash, H. Shekar-Shetty, H.S. Savithri, and C. Sudhakar. 1999. Total peroxidase activity and peroxidase isoforms as modified by salt stress in two cultivars of fox-tail millet with differential salt tolerance. Plant Sci. 141:1-9.

Streb, P. and J. Feierabend. 1996. Oxidative stress responses accompanying photoinactivation of catalase in $\mathrm{NaCl}$-treated rye leaves. Bot. Acta 109:125-132.

Tiburcio, A.F., R.T. Besford, T. Capell, A. Borrell, P.S. Testillano, and M.C. Risueño. 1994. Mechanisms of polyamine action during senescence responses induced by osmotic stress. J. Expt. Bot. 45:1789-1800.

Todd, J.F., G. Paliyath, and J.E. Thompson. 1990. Characteristics of a membrane-associated lipoxygenase in tomato fruit. Plant Physiol. 94:1225-1232.

Van den Broeck, D., D. Van Der Straeten, M. Van Montagu, and A. Caplan. 1994. A group of chromosomal proteins is specifically released by spermine and loses DNA-binding activity upon phosphorylation. Plant Physiol. 106:559-566.

Willekens, H., D. Inzé, M. Van Montagu, and W. van Camp. 1995. Catalases in plants. Mol. Breed. 1:207-228.

Woodbury, W., A.K. Spencer, and M.A. Stahmann. 1971. An improved procedure using ferricyanide for detecting catalase isozymes. Anal. Biochem. 44:301-305. 